\title{
THE ROLE OF THE ATLANTIC IN THE GLOBAL HEAT BUDGET
}

S. Hastenrath

The large-scale setting of the Atlantic Ocean has important climatic implications, communicating as it does with both the Wedell Sea sector of Antarctic and the Arctic basin. In the global perspective, it is through the South Atlantic that the large hydrospheric heat losses of the entire Arctic basin and the adjacent high-latitute North Atlantic must be met. In the Atlantic, the oceanic heat transport is directed northward from high Southern latitudes all the way to the Arctic. Indeed, hydrospheric heat transport in the South Atlantic is directed towards the Equator.

While large amounts of heat are imported from other parts of the World Ocean, the cold surface waters of the South Atlantic limit evaporative heat losses and are thus conducive to large net heat gain through the ocean surface, which in turn further contributes to the northward directed hydrospheric heat transport across the Equator. The annual-mean oceanic surface heat budget in the low-latitude Atlantic is characterized by largest net allwave radiation in the equatorial region, net surface heat loss in the central portions of the North and South Atlantic subtropical gyres, and smallest latent and sensible heat expenditures and therefore largest net oceanic heat gain in a band immediately to the South of the Equator. This limited region acts as a major source of heat to fuel air-sea exchange in the North Atlantic and Arctic basin.

The freshwater budget is through evaporation-precipition processes, intimately related to the heat budget. The large evaporative losses in the North Atlantic, which greatly exceed local precipitation, call for a substantial lateral inflow of freshwater into the greater Atlantic Ocean basin. Not only is the bulk of the river runoff from the surrounding continents directed into the Atlantic, but freshwater is also imported from the Arctic basin, and more substantially from the sub-Antarctic seas. The continuity requirements for freshwater are, in turn, related to the salinity budget.

Among the potentially most sensitive components of the Atlantic Ocean system are the

TUniversity of Wisconsin-Madison, Wisconsin, USA. 
tongue of cold surface waters immediately to the South of the Eastern Atlantic Equator and the Arctic basin. Alterations of heat input in the former, very limited domain may have repercussions on the heat budget in remote regions. An ice-covered Arctic basin would require a much smaller oceanic heat import and accordingly a lesser northward heat transport in the Atlantic, and reduced heat supply from other parts of the World Ocean. The CLMAP paleoreconstructions for $18 \mathrm{Ka}$ lend support to this conjecture.

\section{REFERENCES}

HASTENRATH, S. (1982) On meridional heat transports in the world ocean. Journal of Physical Oceanography, 12:922-927.

HASTENRATH, S. (1988) Climate and circulation of the tropics. 2.ed. Dordrecht, D. Reidel Publ. 455p.

McINTYRE, A. (compiler) Seasonal reconstructions of the earth's surface at the last glacial maximum: map and chart series (Geological Society of America), MC-36, 18p., illus., colored biogeogr.maps, colored paleoclimate maps, 1981.

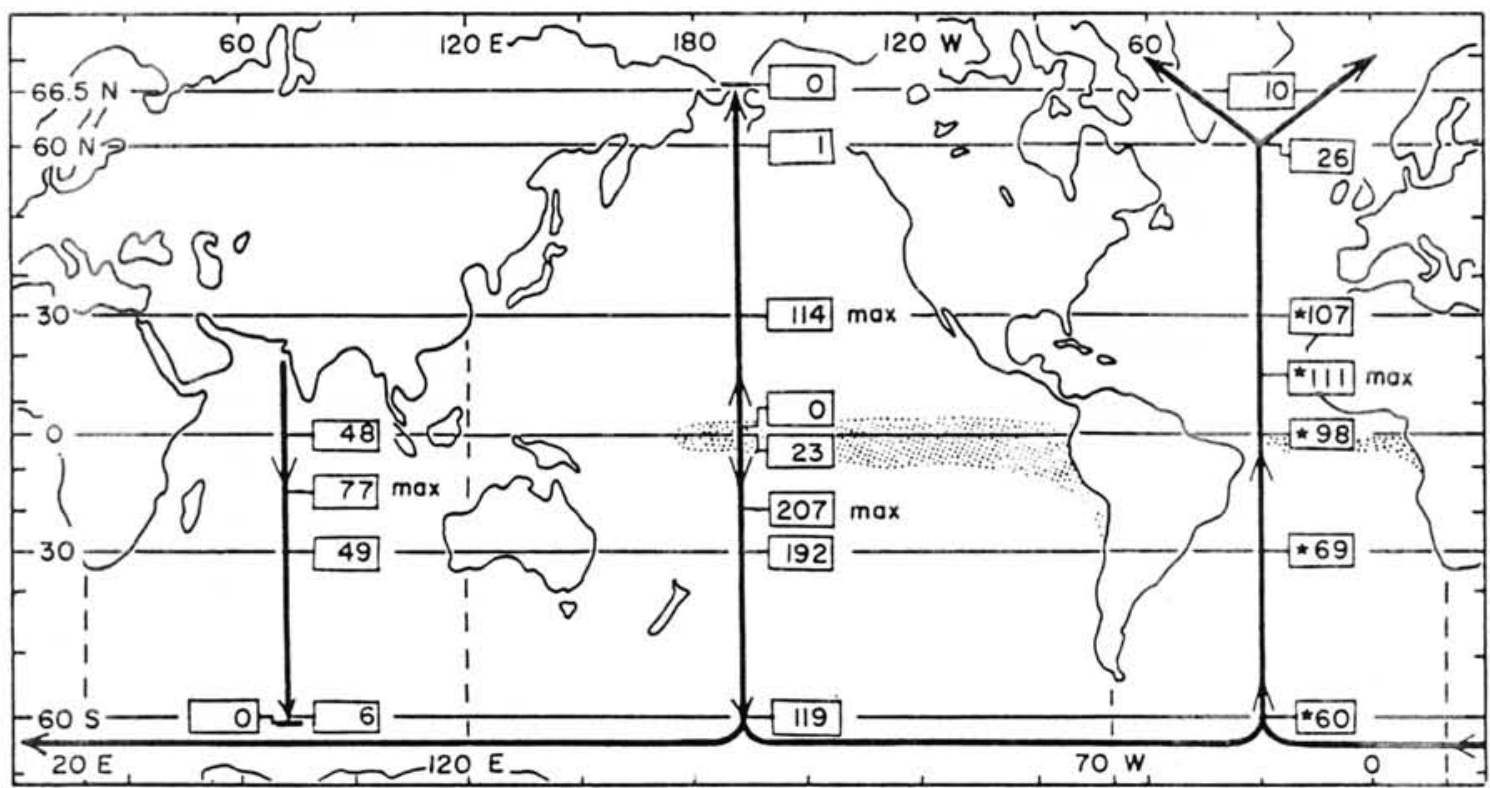

Figure 1 - Map scheme of annual mean meridional heat transport within the oceans. Heavy cross-bar denotes latitude of zero, and "max" that of maximum meridional transport, with numbers indicating amounts in units of $10^{13} \mathrm{~W}$. Stippling marks areas with oceanic heat export larger than $50 \mathrm{~W} \mathrm{~m}^{-2}$, and broken lines show the meridians used a boundaries between oceans in the high southern latitudes. From HASTENRATH $(1982,1988)$. 


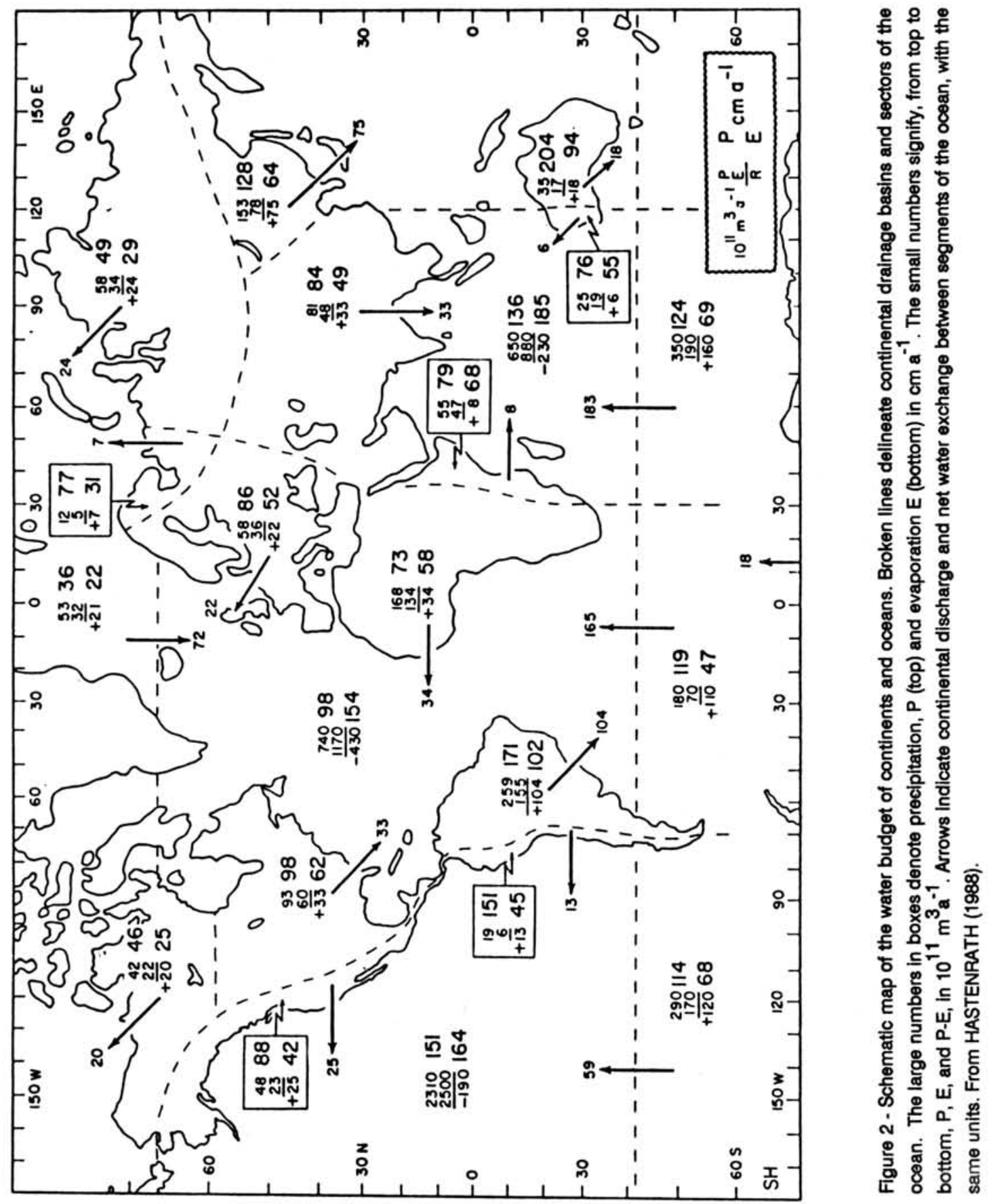




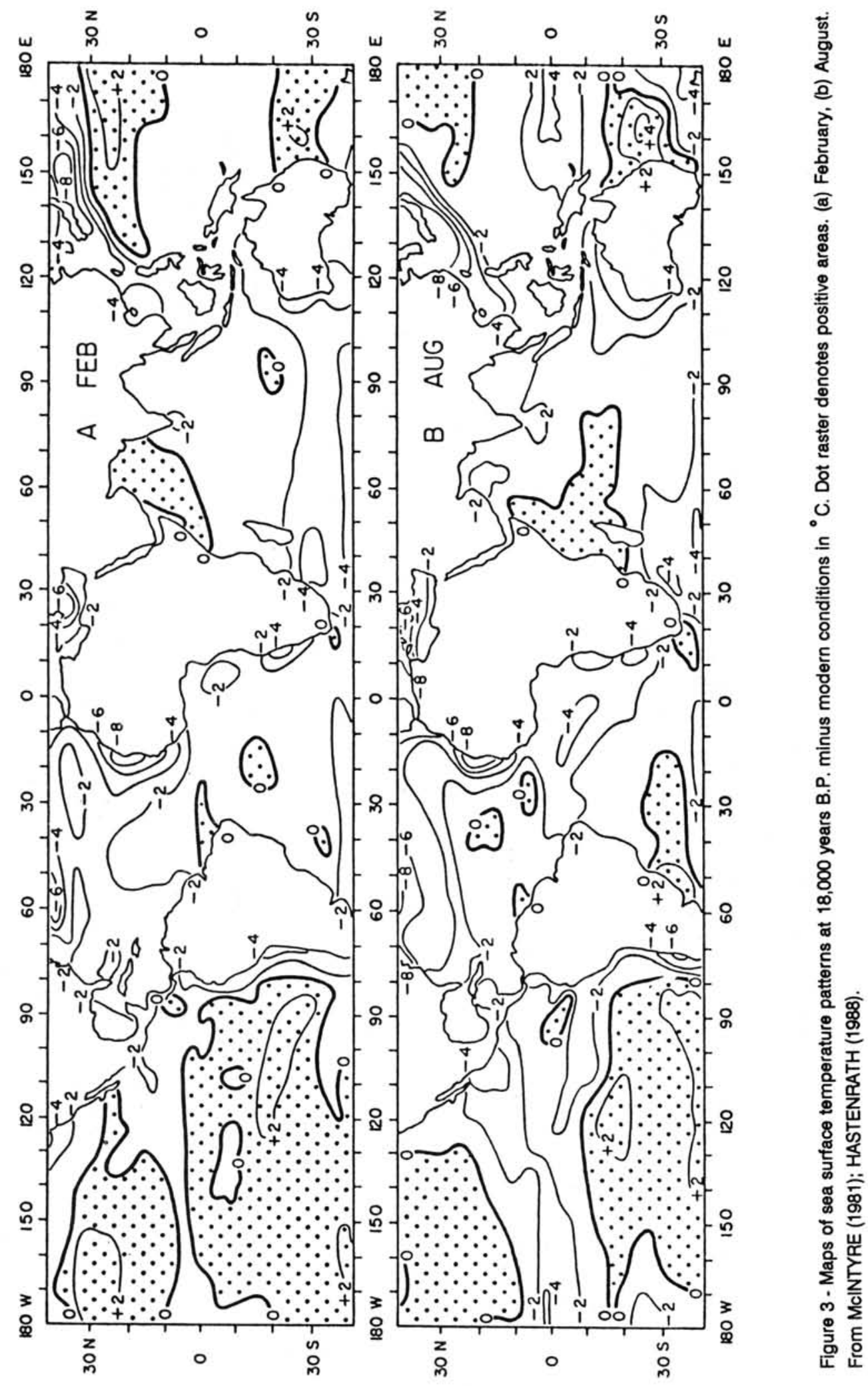

